\title{
Determinants of Modern Contraceptive Utilization Among Married Women In Sub-Saharan Africa: Multilevel Analysis Using Recent Demographic And Health Survey
}

\author{
Zemenu Tadesse Tesema \\ University of Gondar \\ Getayeneh Antehunegn Tesema \\ University of Gondar \\ Moges Muluneh Boke ( $\nabla$ mogelove75@gmail.com ) \\ University of Gondar \\ Temesgen Yihunie Akalu \\ University of Gondar
}

\section{Research Article}

Keywords: modern contraception, family planning, sub-Saharan, multilevel analysis

Posted Date: January 18th, 2022

DOI: https://doi.org/10.21203/rs.3.rs-699121/v2

License: (c) (1) This work is licensed under a Creative Commons Attribution 4.0 International License.

Read Full License 


\section{Abstract}

Background: Family planning is a low-cost, high-impact public health and development strategy to improve child and maternal health. However, there is a lack of evidence on modern contraceptive use and determinants in sub-Saharan Africa. Hence, this study was aimed at determining the pooled prevalence and determinants of modern contraceptive utilization in Sub-Saharan Africa.

Methods: Thirty-six sub-Saharan African countries' demographic and health survey (DHS) data were used for pooled analysis. A total weighted sample of 322,525 married women were included. Cross tabulations and summary statistics were done using STATA version 14 software. The pooled prevalence of modern contraceptive utilization with a $95 \%$ Confidence Interval $(\mathrm{Cl})$ was reported. Four models were fitted to select the best-fitted model using Likelihood Ratio (LLR) and Deviance test. Finally, the model with the highest LLR and the smallest deviance was selected as a best fitted model.

Results: The pooled estimate of modern contraception use in sub-Saharan African countries was $18.36 \%$ [95\% Cl: 18.24, 18.48], with highest in Lesotho (59.79\%) and the lowest in Chad (5.04\%). The odds of modern contraception utilization among women living in East Africa was (AOR=1.47 (1.40, 1.54)), urban $(A O R=1.18(1.14,1.24))$, women primary and secondary and above educational level $(A O R=1.49(1.44$, $1.55))$, and $(A O R=1.66(1.58,1.74))$, respectively. Moreover, husband primary $(A O R=1.38(1.33,1.42))$, middle $(A O R=1.17,(1.14,1.21))$, rich wealth status $(A O R=1.29(1.25,1.34))$, media exposure $(A O R=1.25$ $(1.22,1.29))$, and postnatal care (PNC) utilization ( $A O R=1.25(1.22,1.29))$ had higher odds of modern contraceptive utilization compared with their counter parts. Furthermore, deliver at health facility $(A O R=1.74(1.69,1.79))$ and birth order 2-4 $(A O R=1.36(1.31,1.41))$ had higher odds of modern contraceptive utilization. On the otherhand, women living in Central $(A O R=0.23(0.22,0.24))$, Western regions $(\mathrm{AOR}=0.46(0.40,0.54))$, women decided with husband $(\mathrm{AOR}=0.90(0.87,0.93))$, and husband alone $(A O R=0.73(0.71,0.75))$ were decreased the odds of modern contraceptive utilization.

Conclusion: The uptake of modern contraception in sub-Saharan Africa is low. Modern contraceptive utilization is affected by different factors. More attention need to be given to rural residents, illiterate women, and communities with low wealth status.

\section{Background}

Contraception is the way to prevent pregnancy and assists couples and individuals to achieve their reproductive goals that enable them to exercise their reproductive right, limit the number of children, and reduces maternal and child morbidity and mortality related to complications of unwanted pregnancy (1).

In low and middle-income countries, the burden of maternal mortality ratio (MMR) is projected upto 415 maternal deaths per 100,000 live births, which is sixty times higher than the high-income countries. SubSaharan Africa is the leading in MMR and alone it shares $66 \%$ of the global burden with an estimated 542 maternal deaths per 100,000 live births occur. In sub-Saharan Africa, one woman will die in every 37 women compared to developed countries 1 in 7,800 will die (2). 
In most sub-Saharan countries the total fertility rate (TFR) declined over time; in some countries it remained stagnant. Zimbabwe, Namibia, Liberia, Kenya, Togo, Senegal, Madagascar and Ghana showed the steepest drops in total fertility. However, in a few countries, such as Niger, Nigeria, and Mozambique, the TFR increased or remained steady (3). To accelerate the fertility decrement rate in sub-Saharan countries improving contraception coverage is essential (4).

Today, 1.9 billion women are in the reproductive age group, from which 1.1 billion women were recognized to have a need for family planning, which means they want to limit or delay birth, 851 million of these women use a modern method of contraception, while 85 million use a traditional method, 172 million women have an unmet need for family planning (5).

World reproductive age women (15-49) using contraception has been increased in the last decades but the progress was uneven from place to place. Contraceptive use in Latin and North America, Asia, and Australia range from $60 \%$ to $50 \%$, incontrast in Northern Africa and Western Asia (35.1\%), sub-Saharan Africa (34.1\%) and Oceania (30.7\%) few number of women use contraception(6).

The fulfillment of the sustenable development goals 2030 agenda, such as lowering maternal and under5 mortality, reducing the frequency of pregnancy and childbearing at young ages, increasing educational attainment and reducing the percentage of women and children living in poverty will be aided by an increase in the proportion of women of reproductive age who have their family planning needs to be fulfilled using modern contraception (2).

To improve the access and uptake of contraception, strengthen health-care systems with commodity supply, integrating family planning service in primary health care facilities, community-based distribution (CBD) of contraceptives, strengthening commercial outlet and other activities has been implemented for last several decades (7). Despite access and availability of modern contraception strength, there is no sub-Saharan Africa representative primary data source that provides prevalence and determinants to contraception use. Therefore, determine the pooled prevalence and determinants of modern contraceptive utilization across the Sub-Saharan Africa countries.

\section{Method}

\section{Data Source}

The most recent (from 2006 to 2018) Demographic and Health Surveys (DHS) data were used in the following 36 Sub-Saharan African countries (Table 1). These datasets were used to determine the pooled prevalence and determinants of modern contraception use across countries in Sub-Saharan Africa. The DHS is a national survey that collects information on basic demographic and health indicators such as family planning service use, mortality, morbidity, and mother and child health and fertility. The information came from the DHS measure program. Men, women, children, birth, and household datasets are included in each country's survey; for this study, the IR file was employed. Women data set was used to extract both dependent and independent variables. A two-stage stratified selection procedure was done 
to select study participants. The study contained a total weighted sample of 322,525 married women from 36 DHS surveys conducted in Sub-Saharan African nations in the five years before the survey.

\section{Measurements of variables}

\section{Outcome variable}

The outcome variable for this study was whether a mother uses modern contraceptives or not. The outcome of this study was binary (modern contraceptive use versus non-modern contraceptive). We coded "1" if women utilize modern contraceptives and"0" otherwise.

\section{Explanatory variables}

Based on known facts and literatures the explanatory variables included in this study were Region, residence, age group, literacy level, maternal education, husband education, maternal occupational status, women autonomy on health care, wealth index, media exposure, accessing health care, PNC utilization, place of delivery and birth order.

\section{Data management and analysis}

We integrated data from 36 nations in Sub-Saharan Africa after extracting variables based on literature. Before conducting the statistical analysis, the data was weighted to keep the representativeness of the survey and to get more reliable estimates. STATA version 14 was used to perform cross-tabulations and summary statistics. Moreover, the pooled prevalence of modern contraceptive utilization with a corresponding $95 \%$ confidence interval $(\mathrm{Cl})$ was reported.

\section{Statistical modeling}

The demographic and health survey data has a hierarchical structure for the factors, which violates the usual logistic regression model's assumption; independence of observations and equal variance. Besides, women within a single cluster are expected to be more similar than other clusters in the country. Hence, using multilevel analysis is recommended to take into account the between cluster variability. To address this objective four separate models were fitted. These include the null model, model I (community-level variables, model II (individual-level variable) and Model III (models that include both individual and community level variables) were fitted. The most parsimonious model was selected using LLR and Deviance test. The highest LLR and the lowest deviance was the best-fitted model. Finally, the model includes both individual and community level variables was selected (Table 3 ).

\section{Results}

A total of $\mathbf{3 2 2 , 5 2 5}$ married women five years preceding the survey in 36 sub-Saharan Africa countries were included in this study. Of these, the largest study participants $131,334(40.72 \%)$ were from Western 
Africa Region and the smallest study participants 16071 (4.98\%) were from the Southern Regions of Africa. The majority of study participants 212360 (65.84\%) were rural residents. The median age of women included in his study was $28.8(\mathrm{IQR}=7.2)$ years of which $129,302(40.09 \%)$ of them under the age category 25-34. Thirty-seven percent of women and thirty-nine percent of men had no formal education. More than one-third of women 127562 (39.55\%) were under poor wealth status (Table 2).

\section{The pooled prevalence of modern contraception utilization}

The pooled prevalence of modern contraceptive utilization in sub-Saharan Africa countries was $18.36 \%$ [95\% Cl: 18.24, 18.48], with the highest modern contraceptive utilization in the Southern Region of Africa $(38.43 \%)$ and the low modern contraceptive utilization in Central Regions of Africa (9.46\%). The subgroup analysis result evidenced that in the Southern regions of Africa highest modern contraceptive utilization $59.79 \%$ were recorded in Lesotho and the low modern contraceptive utilization $19.99 \%$ were recorded in Swaziland. In the Central Regions of Africa highest modern contraceptive utilization 33.68\% were recorded in Sao Tome and Principe and the low modern contraceptive utilization 5.04\% were from Chad. In Eastern regions of Africa highest modern contraceptive utilization $65.77 \%$ were recorded in Zimbabwe and the low modern contraceptive utilization 11.34\% were from Mozambique. In the Western Regions of Africa the highest modern contraceptive utilization $22.19 \%$ were from Ghana and the low contraceptive utilization $8 \%$ were from Gambia (Figure 1).

Figure 1 :- Forest plot of modern contraceptive utilization in Sub-Sahara Africa from 2006 to 2018.

\section{Determinants of modern contraceptive utilization}

\section{Random effect analysis}

The results of the random-effects model indicated that there was significant clustering of modern contraceptive utilization across the communities (OR of community-level variance $=0.03,95 \% \mathrm{Cl}=0.024$ 0.038). The intra-class correlation (ICC) in the null model indicated that $5.13 \%$ of the overall variability of modern contraceptive utilization was attributed to cluster variability.

The median odds ratio (MOR) for modern contraceptive utilization was 1.49 in the null model, which indicates that there was a variation in modern contraceptive utilization between clusters. This means if we randomly select women from different clusters, women at the cluster with higher modern contraceptive utilization had 1.49 times higher odds of modern contraceptive utilization as compared with those women at clusters with lower modern contraceptive use.

The Proportional Change in Variance (PCV) also increases from $80 \%$ from model II to $83 \%$ in model III (a model with individual and community level variables), which indicates the last model (model III) best explains the variability of modern contraceptive utilization (Table 3 ). 
In the multilevel multivariable logistic regression model; Sub-Sahara Africa region, residence, maternal education, husband education, women health care decision autonomy, wealth index, media exposure, PNC utilization, place of delivery and birth order were identified as determinants to modern contraceptive utilization.

Women living in Central, and Western Regions of Africa decreased the odds of modern contraceptive utilization by $77 \%$, and $54 \%$ as compared to women living in South Regions of Africa (AOR $=0.23,95 \% \mathrm{Cl}$ : $0.22,0.24)$, and ( $A O R=0.46,95 \% \mathrm{Cl}: 0.40,0.54)$, respectively. The odds of modern contraceptives were increased by $47 \%$ among women living in East Africa as compared to women living in South Africa $(A O R=1.47,95 \% \mathrm{Cl}: 1.40,1.54)$. The odds of modern contraceptive utilization among urban women were increased by $18 \%$ as compared to rural women ( $\mathrm{AOR}=1.18,95 \% \mathrm{Cl}: 1.14,1.24)$.

The odds of modern contraceptive utilization among women who had primary and secondary and above educational level were 1.49 (AOR=1.49, 95\% Cl: 1.44, 1.55) and1.66 (AOR=1.66, 95\% Cl: 1.58, 1.74) times higher as compared to women who had no formal education. The odds of modern contraceptive utilization among women whose husband had primary and secondary and above educational level were $1.38(\mathrm{AOR}=1.38,95 \% \mathrm{Cl}: 1.33,1.42)$ and $1.38(\mathrm{AOR}=1.38,95 \% \mathrm{Cl}: 1.36,1.47)$ times higher as compared to women whose husband had no formal education. The odds of modern contraceptive utilization among women who can decide health care service with their husband and husband alone were decreased $10 \%$ $(\mathrm{AOR}=0.90,95 \% \mathrm{Cl}: 0.87,0.93)$ and $27 \%(\mathrm{AOR}=0.73,95 \% \mathrm{Cl}: 0.71,0.75)$ as compared to women whose health care utilization decided by herself alone.

Women whose wealth status middle and rich were 1.17 (AOR=1.17, $95 \% \mathrm{Cl}: 1.14,1.21$ ) and 1.29 ( $A O R=1.29,95 \% \mathrm{Cl}: 1.25,1.34)$ times more likely to utilize contraceptive than poor women. The odds of contraceptive utilization among media-exposed women were 1.25 times higher than women who did not expose to media (AOR=1.25, 95\% Cl: 1.22, 1.29). The odds of modern contraceptive utilization among women who had PNC utilization were 1.62 times more likely than women who had no PNC utilization $(A O R=1.25,95 \% \mathrm{Cl}: 1.22,1.29)$. The odds of modern contraceptive utilization among women who deliver at the health facility were 1.62 times more likely than women who deliver at home (AOR=1.74, 95\% Cl: $1.69,1.79)$. The odds of contraceptive utilization among women whose birth order $2-4$ and $5+$ were increased by $36 \%(\mathrm{AOR}=1.36,95 \% \mathrm{Cl}: 1.31,1.41)$ and $35 \%(\mathrm{AOR}=1.35,95 \% \mathrm{Cl}: 1.28,1.43)$ as compared to women who had first birth order (Table 3).

\section{Discussion}

In this study, the pooled prevalence of modern contraceptives was $18.36 \%$ (18.23\% - 18.48\%). The highest modern contraceptive utilization was found in the southern Africa region (38.43\%) and the lowest in the central Africa region (9.46\%). This study showed that in the southern Africa region the highest prevalence was noticed in Lesotho (59.79\%) and the lowest in Swaziland (19.99\%). In the Eastern Africa region the overall modern contraceptive prevalence was $35.99 \%$ with the highest and lowest prevalence was found in Zimbabwe (65.77\%) and Mozambique (11.34\%), respectively. The overall modern contraceptive in the 
western Africa region was $13.14 \%$. Of these, the highest prevalence found in Ghana (22.19\%) and the lowest prevalence of modern contraceptives was found in Gambia (8.08\%). The highest prevalence in central Africa (19.99\% in Congo) was lower than the lowest prevalence in many other countries.

This finding is in line with a recent review performed in the SSA (8). Besides, the current study is in line with a study from the 2018 world health organization (WHO) report that showed that 5.4 children were born from a mother (9). This indicates the uptake of modern contraceptives in the SSA region is still low. The finding indicated that modern contraceptive uptake in the SSA region was low. This could be because of repeated conflicts and security issue, the need for a large family, fear of side effects like infertility, religious and cultural restrictions (10), sex preference, spouse consent and support, high level of illiteracy, poverty, and health system barriers in the sub-Saharan Africa region (8). Even though the possible barriers are perfectly preventable, measures applied to ensure adequate uptake of modern contraceptive in the SSA was very limited. Thus, it is of the essence to all SSA countries to ensure the implementation of adequate sustainable measures to increase the uptake of modern contraception. As a result, they will guarantee sustainable global development, poverty alleviation, increased life expectancy, empowering of women, promoting of health through the reduction of maternal mortality, morbidity, unsafe abortion, and improve child survival through birth spacing $(11,12)$.

The African region, residency, maternal education, husband education, the person who provides health care decision making, wealth index, media exposure, PNC utilization, place of delivery, and birth order were significantly associated with modern contraceptive utilization in Sub-Saharan Africa.

The odds of having modern contraceptive was low in the central, eastern, and western Africa region compared with southern Africa region. This study is in agreement with a trend analysis carried out in SSA countries between 1990 and 2014. According to the findings of the former study Southern African region had a faster increase in contraceptive prevalence rate with some countries achieved almost $60 \%$ and trends in completed family size is the lowest compared with other Africa regions. In contrast, the Central Africa region has a steady contraceptive rate and the lowest across the period and had the highest total fertility rate, completed family size, and family size preference. As a result, the progression of modern contraceptive utilization in the central Africa region had a very slow progression increment with many below $20 \%$ as of 2014 (13). The possible reason could be a poor health care system in the central Africa region. For instance a study from Nigeria, Ghana, and Kenya showed that health care indicators including user-fees, type of health facility, visit by a health care worker, adolescent reproductive health, regular availability of health care workers, and the number of professionals working on maternal health would highly valuable in the utilization of modern contraceptive use (14).

Living in urban was associated with a better modern contraceptive utilization compared with the rural counterparts. The possible reason could be women in rural areas had poor service availability and accessibility and they are far from the health facility (15). Besides, women in the rural area were more likely uneducated and they are unable to get the method of their choice. 
In this study, maternal and husband education increases the uptake of modern contraceptives. This finding is in line with a systematic review and meta-analysis carried out in SSA countries between 2005 and 2015 (16). Similarly, trend analysis in contraceptive prevalence in SSA showed that women's education was strongly correlated with the high level of contraceptive uptake (17). This could be due to the fact that education is the power and a precursor to developing women's empowerment through improving their knowledge and attitude (18). Also, education creates a good job opportunity or employment that could cause child spacing (19) which further improves child survival (20). However, the former study revealed that the mere presence of female education was not adequate and it is highly recommending emphasizing the presence of voluntarily family planning services was strongly associated with an increase in the prevalence of contraceptive use.

Women's health care decision-making autonomy was significantly affecting the odds of modern contraceptive uptake. Women who decide with their husbands had higher odds of modern contraceptive uptake than women who decide alone. This could be when women are unable to decide by themselves their rights and the ability to choose and use the method was worse. Empowering women would enhance women's decision-making ability and increasing their knowledge level that can further improve modern contraceptive uptake (21). As a result, the maternal health outcome and child health would be improved in Sub-Saharan Africa.

The odds of having modern contraceptive uptake were higher among women with a higher wealth index. This finding was supported by a cross-sectional study conducted in sub-Saharan Africa countries using Kenya and Zimbabwe demographic and health survey data (22). The possible explanation could be women from middle and high wealth index have better financial resources which are very helpful to get better access to reproductive health services including modern contraceptive uptake (23).

Mass media exposure was associated with higher odds of modern contraceptive uptake. This finding was supported by a systematic review and meta-analysis conducted among 31 sub-Saharan African countries using 47 demographic and health surveys conducted between 2005 and 2015 (24). The possible reason could be mass media exposure can expose people to information $(25,26)$ and overcoming barriers of illiteracy and improve the knowledge and attitude of women (27).

The current study showed that mothers who had PNS services had higher odds of utilizing modern contraceptives. The possible reason could be during PNC follow-up mothers' have the opportunity to communicate with providers and to receive counseling regarding on initiation of postpartum contraceptive services $(28,29)$. Similarly, mothers' who delivered at health institution has higher odds of uptake of modern contraceptive. This is because at the health institution mothers' have the opportunity to get information on when and why they initiate postpartum contraception (30). Birth orders of two or more had higher odds of modern contraceptive intake than birth order one. This because women's having more children had the intention to have birth spacing than women's having a single child or fewer children.

The strength of the current study was incorporating 36 sub-Saharan Africa countries and the findings can be easily generalized to the SSA at large. However, it is difficult to establish a temporal relationship 
because of the cross-sectional nature of the study. Moreover, data related to the availability and accessibility of the service was not collected. Lastly, the study will be prone to recall and social desirability bias as most of the health measures in DHS are based on self-report.

The uptake of modern contraceptive utilization has a valuable contribution to the general public and the country at large. As a result, the public will be benefitted through maintaining health promotion including reduction of poor maternal outcomes (maternal morbidity, mortality, and abortion) and in poverty mitigation, women empowerment, increased life expectancy, keeping gender equality, and realizing sustainable global development goals. Besides, child survival will be improved through birth spacing and has a great contribution in creating a better future for the coming generations.

\section{Conclusion}

This study indicated that low modern contraception utilization in sub-Saharan Africawas low. Women living in the east, central, western region, urban, educational level, wealth status, media exposure, having PNC utilization, deliver at the health facility, and having more birth order, women decision making ability were significantly associated with modern contraception utilization. More attention need to be given to rural residents, illiterate women, and communities with low wealth status. Moreover, postnatal care and health facility delivery activities need to be strengthen.

\section{Abbreviations}

AIDS: Acquired Immune Deficiency Syndrome; AOR: Adjusted Odd Ratio; CBD: Community-Based Distribution; Cl: Confidence Interval; COR: Crude Odd Ratio; DHS: Demographic and Health Survey; ICC: Intra-Class Correlation; HIV: Human Immune Virus; IQR: Inter Quartile Range; LLR: Likelihood Ratio; MMR: Maternal Mortality Ratio; MOR: Median Odds Ratio; PCV: Proportional Change in Variance; PNC: Postnatal care; SSA: Sub-Saharan Africa; TFR: Total Fertility Rate

\section{Declarations}

\section{Ethics consideration}

Permission to get access to the data was obtained from the measure DHS program online request from http://www.dhsprogram.com.website and the data used were publicly available with no personal identifier. Moreover, the study conducted according to the ethical principles and regulations of the country.

\section{Consent for Publication}

Not Applicable

\section{Availability of data and material}


Data is available online on www.measuredhs.com

\section{Competing interests}

Authors declare that there is no conflict of interest

\section{Funding}

This study was not funded

\section{Authors' contributions}

ZTT conceived of the study, analyze the data, and drafted the manuscript. GAT MMB and TYA performed the statistical analysis and drafted the manuscript. All authors read and approved the final manuscript.

\section{Ethics consideration}

Permission to get access to the data was obtained from the measure DHS program online request from http://www.dhsprogram.com.website and the data used were publicly available with no personal identifier.

\section{Acknowledgments}

We would like to thank the Measure DHS International program for providing the data set.

\section{References}

1. Bongaarts J, Cleland JC, Townsend J, Bertrand JT, Gupta MD. Family planning programs for the $21 \mathrm{st}$ century: rationale and design. 2012.

2. Organization WH. Trends in maternal mortality 2000 to 2017: estimates by WHO, UNICEF, UNFPA, World Bank Group and the United Nations Population Division. 2019.

3. Cleland JG, Ndugwa RP, Zulu EM. Family planning in sub-Saharan Africa: progress or stagnation? Bulletin of the World Health Organization. 2011;89:137-43.

4. Bongaarts J. Trends in fertility and fertility preferences in sub-Saharan Africa: the roles of education and family planning programs. Genus. 2020;76(1):1-15.

5. Bongaarts J. United Nations Department of Economic and Social Affairs, Population Division World Family Planning 2020: Highlights United Nations Publications, 2020. 46 p. Wiley Online Library; 2020.

6. United Nations Department of Economic and Social Affairs, Population Division (2020). World Family Planning 2020 Highlights: Accelerating action to ensure universal access to family planning (ST/ESA/SER.A/450). 
7. Aliyu AA. Family planning services in Africa: The successes and challenges. Family Planning. 2018;69.

8. Adedze M, Osei-Yeboah R. Underuse of modern contraception in sub-Saharan Africa: are there implications for sustainable development and climate change? A review of the literature. The European journal of contraception \& reproductive health care : the official journal of the European Society of Contraception. 2019;24(4):314-8.

9. WHO. Family planning/contraception. 2018 (published Oct 30, 2018). http://www.who.int/newsroom/fact-sheets/detail/family-planningcontraception (accessed August 20, 2020).

10. Muanda M, Gahungu Ndongo P, Taub LD, Bertrand JT. Barriers to Modern Contraceptive Use in Kinshasa, DRC. PloS one. 2016;11(12):e0167560.

11. Cleland J, Bernstein S, Ezeh A, Faundes A, Glasier A, Innis J. Family planning: the unfinished agenda. Lancet 2006; 368: 1810-27.

12. Osotimehin B. Family planning as a critical component of sustainable global development. Glob Health Action 2015; 8: 29978.v.

13. Odimegwu CO, Akinyemi JO, Banjo OO, Olamijuwon E, Amoo EO. Fertility, Family Size Preference and Contraceptive Use in Sub-Saharan Africa: 1990-2014. African journal of reproductive health. 2018;22(4):44-53.

14. Asaolu I, Nuño VL, Ernst K, Taren D, Ehiri J. Healthcare system indicators associated with modern contraceptive use in Ghana, Kenya, and Nigeria: evidence from the Performance Monitoring and Accountability 2020 data. Reproductive health. 2019;16(1):152.

15. Shiferaw S, Spigt M, Seme A, Amogne A, Skrøvseth S, Desta S, et al. Does proximity of women to facilities with better choice of contraceptives affect their contraceptive utilization in rural Ethiopia? PloS one. 2017;12(11):e0187311.

16. Blackstone SR, Nwaozuru U, Iwelunmor J. Factors Influencing Contraceptive Use in Sub-Saharan Africa: A Systematic Review. International quarterly of community health education. 2017;37(2):79-91.

17. Bongaarts J, Hardee K. Trends in Contraceptive Prevalence in Sub-Saharan Africa: The Roles of Family Planning Programs and Education. African journal of reproductive health. 2019;23(3):96-105.

18. Arinze-Onyia SU, Aguwa EN, Nwobodo E. Health education alone and health education plus advance provision of emergency contraceptive pills on knowledge and attitudes among university female students in Enugu, Nigeria. Nigerian journal of clinical practice. 2014;17(1):100-5.

19. al-Nahedh NN. The effect of sociodemographic variables on child-spacing in rural Saudi Arabia. Eastern Mediterranean health journal $=$ La revue de sante de la Mediterranee orientale $=$ al-Majallah alsihhiyah li-sharq al-mutawassit. 1999;5(1):136-40. 
20. Akter S, Rahman JA, Rahman MM, Abedin S, al-Nahedh NN. The influence of birth spacing on child survival in Bangladesh: a life table approach

The effect of sociodemographic variables on child-spacing in rural Saudi Arabia. World health \& population. 2010;12(1):42-56.

21. Estrada F, Hernández-Girón $C$, Walker D, Campero L, Hernández-Prado B, Maternowska C. [Use of family planning services and its relationship with women's decision-making and support from their partner]. Salud publica de Mexico. 2008;50(6):472-81.

22. Chikandiwa A, Burgess E, Otwombe K, Chimoyi L. Use of contraceptives, high risk births and under-five mortality in Sub Saharan Africa: evidence from Kenyan (2014) and Zimbabwean (2011) demographic health surveys. BMC women's health. 2018;18(1):173.

23. Sharma V, Mohan U, Das V, Awasthi S. Socio demographic determinants and knowledge, attitude, practice: survey of family planning. J Fam Med Prim Care. 2012;1(1):43-7.

24. Babalola S, Figueroa ME, Krenn S. Association of Mass Media Communication with Contraceptive Use in Sub-Saharan Africa: A Meta-Analysis of Demographic and Health Surveys. Journal of health communication. 2017;22(11):885-95.

25. Islam MM, Hasan AH. Mass media exposure and its impact on family planning in Bangladesh. Journal of biosocial science. 2000;32(4):513-26.

26. Adamchak DJ, Mbizvo MT. Family planning information sources and media exposure among Zimbabwean men. Studies in family planning. 1991;22(5):326-31.

27. Gupta N, Katende C, Bessinger R. Associations of mass media exposure with family planning attitudes and practices in Uganda. Studies in family planning. 2003;34(1):19-31.

28. Engin-Ustun Y, Ustun Y, Cetin F, Meydanli MM, Kafkasli A, Sezgin B. Efect of postpartum counseling on postpartum contraceptive use. Arch Gynecol Obstet. 2007;275(6):429-32.

29. Do M, Hotchkiss D. Relationships between antenatal and postnatal care and post-partum modern contraceptive use: evidence from population surveys in Kenya and Zambia. BMC Health Serv Res. 2013;13:6.

30. Darney BG, Sosa-Rubi SG, Servan-Mori E, Rodriguez MI, Walker D, Lozano R. The relationship of age and place of delivery with postpartum contraception prior to discharge in Mexico: A retrospective cohort study. Contraception. 2016;93(6):478-84.

\section{Tables}


Table 1: Pooled Demographic and Health Surveys (DHS) data from 36 sub-Saharan countries, 20062018. 


\begin{tabular}{|c|c|c|}
\hline Country & DHS year & Sample size $(322,525)$ \\
\hline Southern Region of Africa & & 16071 \\
\hline Lesotho & 2014 & 3612 \\
\hline Namibia & 2013 & 3120 \\
\hline Swaziland & $2006 / 07$ & 6289 \\
\hline South Africa & 2016 & 3049 \\
\hline Central Region of Africa & & 55588 \\
\hline Angola & $2015 / 16$ & 7956 \\
\hline DR Congo & $2013 / 14$ & 12095 \\
\hline Congo & $2011 / 12$ & 6289 \\
\hline Cameroon & 2011 & 9791 \\
\hline Gabon & 2012 & 4474 \\
\hline Sao Tome \& Principe & 2008/09 & 1718 \\
\hline Chad & $2014 / 15$ & 13262 \\
\hline Eastern region of Africa & & 119530 \\
\hline Burundi & 2010 & 9781 \\
\hline Ethiopia & 2016 & 10223 \\
\hline Kenya & 2014 & 18549 \\
\hline Comoros & 2012 & 3261 \\
\hline Madagascar & 2008/09 & 12038 \\
\hline Malawi & $2015 / 16$ & 16130 \\
\hline Mozambique & 2011 & 9331 \\
\hline Rwanda & $2014 / 15$ & 6981 \\
\hline Tanzania & $2015 / 16$ & 8210 \\
\hline Uganda & 2011 & 11223 \\
\hline Zambia & 2018 & 7648 \\
\hline Zimbabwe & $2013 / 14$ & 6151 \\
\hline Western Region of Africa & & 131334 \\
\hline Burkina-Faso & 2010 & 13563 \\
\hline
\end{tabular}




\begin{tabular}{|lll|}
\hline Benin & 2017 & 11168 \\
\hline Gote d'Ivoire & 2011 & 6308 \\
\hline Gambia & 2014 & 5321 \\
\hline Guinea & 2013 & 6791 \\
\hline Liberia & 2018 & 7727 \\
\hline Mali & 2013 & 5385 \\
\hline Nigeria & 2018 & 8567 \\
\hline Niger & 2018 & 29089 \\
\hline Sierra Leone & 2012 & 9880 \\
\hline Senegal & $2010 / 11$ & 10902 \\
\hline Togo & $2010 / 11$ & 10346 \\
\hline
\end{tabular}

Table 2: - Distribution of modern contraceptive utilization in sub-Saharan Africa region 


\begin{tabular}{|c|c|c|c|c|c|}
\hline \multirow[t]{3}{*}{ Variable } & \multirow{2}{*}{\multicolumn{2}{|c|}{$\begin{array}{l}\text { Modern } \\
\text { contraceptive } \\
\text { Utilization }\end{array}$}} & \multirow[t]{3}{*}{ Total (\%) } & \multirow[t]{3}{*}{$\begin{array}{l}X \text {-square } \\
\text { value }\end{array}$} & \multirow[t]{3}{*}{$\begin{array}{l}\text { p- } \\
\text { value }\end{array}$} \\
\hline & & & & & \\
\hline & Yes & No & & & \\
\hline \multicolumn{6}{|l|}{ Africa Region } \\
\hline Southern & 6789 & 9282 & $16,071(4.98)$ & \multirow[t]{4}{*}{163.79} & \multirow[t]{4}{*}{$<0.001$} \\
\hline Central & 6728 & 48860 & $55,588(17.24)$ & & \\
\hline Eastern & 47646 & 71883 & $\begin{array}{l}119,530 \\
(37.66)\end{array}$ & & \\
\hline Western & 17936 & 113397 & $\begin{array}{l}131,334 \\
(40.72)\end{array}$ & & \\
\hline \multicolumn{6}{|l|}{ Residence } \\
\hline Rural & 47359 & 165001 & $\begin{array}{l}212,360 \\
(65.84)\end{array}$ & \multirow[t]{2}{*}{46.19} & \multirow[t]{2}{*}{$<0.001$} \\
\hline Urban & 31742 & 78422 & $\begin{array}{l}110,165 \\
(34.16)\end{array}$ & & \\
\hline \multicolumn{6}{|l|}{ Age group } \\
\hline $15-24$ & 16472 & 62396 & $78,868(24.45)$ & \multirow[t]{3}{*}{20.08} & \multirow[t]{3}{*}{$<0.001$} \\
\hline $25-34$ & 35393 & 93908 & $\begin{array}{l}129,302 \\
(40.09)\end{array}$ & & \\
\hline $35-46$ & 27235 & 87119 & $\begin{array}{l}114,355 \\
(35.46)\end{array}$ & & \\
\hline \multicolumn{6}{|l|}{ Literacy } \\
\hline Cannot read and write & 23822 & 140763 & $\begin{array}{l}164,585 \\
(51.03)\end{array}$ & 103.73 & $<0.001$ \\
\hline Can read and write & 55279 & 102660 & $\begin{array}{l}157,940 \\
(48.97)\end{array}$ & & \\
\hline \multicolumn{6}{|l|}{ Maternal education } \\
\hline No education & 15384 & 111585 & $\begin{array}{l}126,969 \\
(39.37)\end{array}$ & \multirow[t]{3}{*}{103.73} & \multirow[t]{3}{*}{$<0.001$} \\
\hline Primary education & 33176 & 72974 & $106,151(32.91)$ & & \\
\hline Secondary and above & 30541 & 58861 & $89,405(27.72)$ & & \\
\hline \multicolumn{6}{|l|}{ Husband education } \\
\hline No education & 13905 & 98391 & $\begin{array}{l}112,296 \\
(35.95)\end{array}$ & 70.97 & $<0.001$ \\
\hline
\end{tabular}




\begin{tabular}{|c|c|c|c|c|c|}
\hline Primary education & 26193 & 60678 & $86,871(27.81)$ & & \\
\hline Secondary and above & 33694 & 79478 & $\begin{array}{l}113,173 \\
(36.24)\end{array}$ & & \\
\hline \multicolumn{6}{|l|}{ Maternal Occupation } \\
\hline Had occupation & 60594 & 182407 & $\begin{array}{l}243,001 \\
(75.34)\end{array}$ & \multirow[t]{2}{*}{152.34} & \multirow[t]{2}{*}{$<0.001$} \\
\hline Had no occupation & 18507 & 61017 & $79,524(24.66)$ & & \\
\hline \multicolumn{6}{|c|}{$\begin{array}{l}\text { Women's health care decision making } \\
\text { autonomy }\end{array}$} \\
\hline Women alone & 17865 & 38350 & $56,216(17.43)$ & \multicolumn{2}{|l|}{118.50} \\
\hline Women and her husband & 33837 & 84186 & $\begin{array}{l}118,024 \\
(36.59)\end{array}$ & & $<0.001$ \\
\hline Husbands alone & 27398 & 120886 & $\begin{array}{l}148,284 \\
(45.98)\end{array}$ & & \\
\hline \multicolumn{6}{|l|}{ Wealth Index } \\
\hline Poor & 23500 & 104061 & $\begin{array}{l}127,562 \\
(39.55)\end{array}$ & \multirow[t]{3}{*}{124.50} & \multirow[t]{3}{*}{$<0.001$} \\
\hline Middle & 15318 & 48697 & $64,015(19.85)$ & & \\
\hline Rich & 40282 & 90665 & $\begin{array}{l}130,947 \\
(40.60)\end{array}$ & & \\
\hline \multicolumn{6}{|l|}{ Media Exposed } \\
\hline Yes & 61967 & 158840 & $\begin{array}{l}220,807 \\
(68.46)\end{array}$ & \multirow[t]{2}{*}{112.47} & \multirow[t]{2}{*}{$<0.001$} \\
\hline No & 17134 & 84583 & $\begin{array}{l}101,718 \\
(31.54)\end{array}$ & & \\
\hline \multicolumn{6}{|l|}{ Accessing health care } \\
\hline Big problem & 40513 & 143803 & $\begin{array}{l}184,316 \\
(57.15)\end{array}$ & \multirow[t]{2}{*}{38.16} & \multirow[t]{2}{*}{$<0.001$} \\
\hline Not big problem & 38588 & 99620 & $\begin{array}{l}138,209 \\
(42.85)\end{array}$ & & \\
\hline \multicolumn{6}{|l|}{ PNC utilization } \\
\hline Yes & 26673 & 57748 & $\begin{array}{l}113,799 \\
(57.41)\end{array}$ & \multirow[t]{2}{*}{62.26} & \multirow[t]{2}{*}{$<0.001$} \\
\hline No & 23777 & 90021 & $8,441(42.59)$ & & \\
\hline Place of delivery & & & & & \\
\hline
\end{tabular}




\begin{tabular}{|c|c|c|c|c|c|}
\hline Home & 11266 & 69960 & $75,227(31.26)$ & 136.58 & $<0.001$ \\
\hline Institution & 49199 & 116214 & $\begin{array}{l}165,413 \\
(68.74)\end{array}$ & & \\
\hline \multicolumn{6}{|l|}{ Birth Order } \\
\hline 1 & 11661 & 35991 & $47,652(14.81)$ & \multirow[t]{3}{*}{68.29} & \multirow[t]{3}{*}{$<0.001$} \\
\hline $2-4$ & 41817 & 101145 & $\begin{array}{l}142,963 \\
(44.43)\end{array}$ & & \\
\hline $5+$ & 25440 & 105698 & $\begin{array}{l}131,138 \\
(40.76)\end{array}$ & & \\
\hline \multicolumn{6}{|c|}{ Children ever born } \\
\hline 0 & 1544 & 21044 & $22,588(7.00)$ & 92.39 & $<0.001$ \\
\hline $1-3$ & 41890 & 107871 & $149,761(46.43)$ & & \\
\hline $4+$ & 35667 & 114508 & $\begin{array}{l}150,175 \\
(46.56)\end{array}$ & & \\
\hline
\end{tabular}

Table 3: Determinants of modern contraceptive uptake among married women in sub-Saharan Africa 


\begin{tabular}{|c|c|c|c|c|}
\hline \multirow[t]{2}{*}{ Variable } & Null Model & Model I & Model II & Model III \\
\hline & AOR (95\%Cl) & AOR (95\%Cl) & AOR (95\%Cl) & AOR $(95 \% \mathrm{Cl})$ \\
\hline \multicolumn{5}{|l|}{ Africa Region } \\
\hline Southern & & 1 & & 1 \\
\hline Central & & $0.17(0.16,0.17)$ & & $0.23(0.22,0.24)^{\star}$ \\
\hline Eastern & & $1.00(0.96,1.03)$ & & $1.47(1.40,1.54)^{\star}$ \\
\hline Western & & $0.23(0.22,0.24)$ & & $0.46(0.43,0.48)^{\star}$ \\
\hline \multicolumn{5}{|l|}{ Residence } \\
\hline Rural & & 1 & & 1 \\
\hline Urban & & $1.77(1.73,1.83)$ & & $1.18(1.14,1.24)^{\star}$ \\
\hline \multicolumn{5}{|l|}{ Age group } \\
\hline $15-24$ & & & 1 & 1 \\
\hline $25-34$ & & & $1.06(1.02,1.08)$ & $0.99(0.96,1.02)$ \\
\hline $35-46$ & & & $0.99(0.95,1.04)$ & $0.92(0.88,1.01)$ \\
\hline \multicolumn{5}{|l|}{$\begin{array}{l}\text { Maternal } \\
\text { education }\end{array}$} \\
\hline No education & & & 1 & 1 \\
\hline Primary education & & & $1.62(1.57,1.68)$ & $1.49(1.44,1.55)^{\star}$ \\
\hline $\begin{array}{l}\text { Secondary and } \\
\text { above }\end{array}$ & & & $1.43(1.36,1.49)$ & $1.66(1.58,1.74)^{\star}$ \\
\hline \multicolumn{5}{|l|}{$\begin{array}{l}\text { Husband } \\
\text { education }\end{array}$} \\
\hline No education & & & 1 & 1 \\
\hline Primary education & & & $1.84(1.78,1.90)$ & $1.38(1.33,1.42)^{\star}$ \\
\hline $\begin{array}{l}\text { Secondary and } \\
\text { above }\end{array}$ & & & $1.36(1.31,1.41)$ & $1.38(1.33,1.43)^{\star}$ \\
\hline \multicolumn{5}{|l|}{$\begin{array}{l}\text { Maternal } \\
\text { Occupation }\end{array}$} \\
\hline $\begin{array}{l}\text { Had no } \\
\text { occupation }\end{array}$ & & & 1 & 1 \\
\hline Had occupation & & & $0.86(0.84,0.88)$ & $0.94(0.91,1.01)$ \\
\hline
\end{tabular}




\section{making \\ autonomy}

Women alone

Women and her

husband

Husbands alone

Wealth Index

Poor

Middle

Rich

Media Exposed

No

Yes

Accessing health

care

Big problem

Not big problem

\section{PNC utilization}

No

Yes

\section{Place of delivery}

Home

Institution

\section{Birth Order}

\section{1}

2-4

$5+$

Community

$0.17(0.15,0.20)$

$0.068(0.05,0.08)$

1

$1.14(1 \cdot 10,1.17)$

1.35(1.31,1.38)

$1.17(1.14,1.21)^{\star}$

$1.29(1.25,1.34)^{\star}$

1

$1.21(1.18,1.24)$
1

$0.90(0.87,0.93)$ *

$0.73(0.71,0.75)^{\star}$
$0.50(0.48,0.51)$

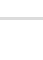




\begin{tabular}{|lllll|}
\hline PCV\% & 1 & 88.23 & 80.22 & 83.05 \\
\hline MOR & $1.49(1.42,1.53)$ & $1.28(1.23,1.30)$ & $1.19(1.17,1.22)$ & $1.17(1.15,1.19)$ \\
\hline LL & & & & \\
\hline Deviance & -175175 & -158668 & -97036 & -91641 \\
\hline AIC & 350350 & 317336 & 194072 & 183282 \\
\hline BIC & 350354 & 317349 & 194114 & 183332 \\
\hline
\end{tabular}

Figures

Prevalence of modern contraceptive in Sub-Saharan Africa

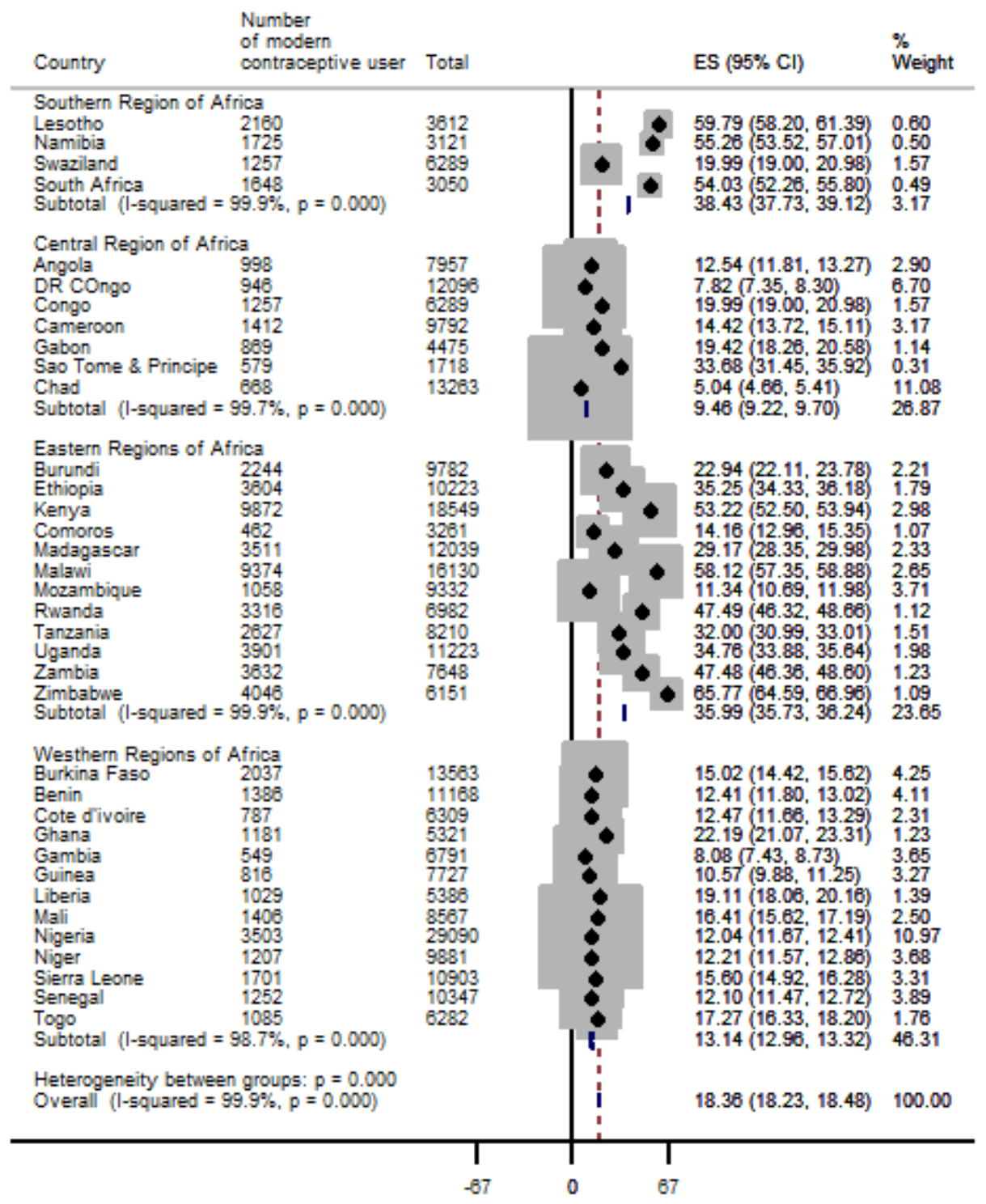




\section{Figure 1}

Forest plot of modern contraceptive utilization in Sub-Sahara Africa from 2006 to 2018. 